Published in final edited form as:

Am J Sports Med. 2016 July ; 44(7): 1671-1679. doi:10.1177/0363546516644218.

\title{
Meniscal and Articular Cartilage Predictors of Clinical Outcome Following Revision Anterior Cruciate Ligament Reconstruction
}

\section{MARS GROUP}

\author{
Abstract \\ Background-Revision anterior cruciate ligament (ACL) reconstruction has been documented to \\ have worse outcomes compared to primary ACL reconstructions. The purpose of this study was to
}

Corresponding Author: Rick W. Wright, MD, Washington University, Department of Orthopaedic Surgery, 660 South Euclid Avenue, Campus Box 8233, St. Louis, MO 63110,314-747-2639,wright@wudosis.wustl.edu.

MARS GROUP: Rick W. Wright, MD (Washington University, St Louis); Laura J. Huston, MS (Vanderbilt University); Sam K. Nwosu, MS (Vanderbilt University); Amanda K. Haas, MA (Washington University, St Louis); Christina R. Allen, MD (University of California, San Francisco); Allen F. Anderson, MD (Tennessee Orthopaedic Alliance); Daniel E. Cooper, MD (W.B. Carrell Memorial Clinic); Thomas M. DeBerardino, MD (University of Connecticut Health Center); Warren R. Dunn, MD, MPH (University of Wisconsin); Brett A. Lantz, MD (Slocum Research and Education Foundation); Barton Mann, PhD (AOSSM); Kurt P. Spindler, MD (Cleveland Clinic); Michael J. Stuart, MD (Mayo Clinic Rochester); John P. Albright, MD (University of Iowa Hospitals and Clinics); Annunziato Amendola, MD (University of Iowa Hospitals and Clinics); Jack T. Andrish, MD (Cleveland Clinic); Christopher C. Annunziata, MD (Commonwealth Orthopaedics \& Rehabiliation); Robert A. Arciero, MD (University of Connecticut Health Center); Bernard R. Bach Jr, MD (Rush University Medical Center); Champ L. Baker III, MD (The Hughston Clinic); Arthur R. Bartolozzi, MD (3B Orthopaedics, University of Pennsylvania Health System); Keith M. Baumgarten, MD (Orthopedic Institute); Jeffery R. Bechler, MD (University Orthopedic Associates LLC); Jeffrey H. Berg, MD (Town Center Orthopaedic Associates); Geoffrey A. Bernas, MD (State University of New York at Buffalo); Stephen F. Brockmeier, MD (University of Virginia); Robert H. Brophy, MD (Washington University, St Louis); Charles A. Bush-Joseph, MD (Rush University Medical Center); J. Brad Butler V, MD (Orthopedic and Fracture Clinic); John D. Campbell, MD (Bridger Orthopaedic and Sports Medicine); James L. Carey, MD, MPH (University of Pennsylvania); James E. Carpenter, MD (University of Michigan); Brian J. Cole, MD (Rush University Medical Center); Jonathan M. Cooper, DO (HealthPartners Specialty Clinic); Charles L. Cox, MD, MPH (Vanderbilt University); R. Alexander Creighton, MD (University of North Carolina Medical Center); Diane L. Dahm, MD (Mayo Clinic Rochester); Tal S. David, MD (Arthroscopic and Orthopedic Sports Medicine Associates); David C. Flanigan, MD (The Ohio State University); Robert W. Frederick, MD (The Rothman Institute/Thomas Jefferson University); Theodore J. Ganley, MD (Children's Hospital of Philadelphia); Elizabeth A. Garofoli (Washington University, St Louis); Charles J. Gatt Jr, MD (University Orthopedic Associates LLC); Steven R. Gecha, MD (Princeton Orthopaedic Associates); James Robert Giffin, MD (Fowler Kennedy Sports Medicine Clinic-University of Western Ontario); Sharon L. Hame, MD (David Geffen School of Medicine at UCLA); Jo A. Hannafin, MD, PhD (Hospital for Special Surgery); Christopher D. Harner, MD (University of Pittsburgh Medical Center); Norman Lindsay Harris Jr, MD (Orthopaedic Associates of Aspen \& Glenwood); Keith S. Hechtman, MD (UHZ Sports Medicine Institute); Elliott B. Hershman, MD (Lenox Hill Hospital); Rudolf G. Hoellrich, MD (Slocum Research and Education Foundation); Timothy M. Hosea, MD (University Orthopedic Associates LLC); David C. Johnson, MD (National Sports Medicine Institute); Timothy S. Johnson, MD (National Sports Medicine Institute); Morgan H. Jones, MD (Cleveland Clinic); Christopher C. Kaeding, MD (The Ohio State University); Ganesh V. Kamath, MD (University of North Carolina Medical Center); Thomas E. Klootwyk, MD (Methodist Sports Medicine Center- The Orthopedic Specialists); Bruce A. Levy, MD (Mayo Clinic Rochester); C. Benjamin Ma, MD (University of California, San Francisco); G. Peter Maiers II, MD (Methodist Sports Medicine Center-The Orthopedic Specialists); Robert G. Marx, MD (Hospital for Special Surgery); Matthew J. Matava, MD (Washington University, St Louis); Gregory M. Mathien, MD (Knoxville Orthopedic Clinic); David R. McAllister, MD (David Geffen School of Medicine at UCLA); Eric C. McCarty, MD (University of Colorado Denver School of Medicine); Robert G. McCormack, MD (University of British Columbia);Bruce S. Miller, MD, MS (University of Michigan); Carl W. Nissen, MD (Connecticut Children's Medical Center); Daniel F. O'Neill, MD, EdD (Littleton Regional Hospital); Brett D. Owens, MD (Brown Alpert Medical School, Providence, RI); Richard D. Parker, MD (Cleveland Clinic); Mark L. Purnell, MD (Orthopaedic Associates of Aspen \& Glenwood); Arun J. Ramappa, MD (Beth Israel Deaconess Medical Center); Michael A. Rauh, MD (State University of New York at Buffalo); Arthur C. Rettig, MD (Methodist Sports Medicine Center-The Orthopedic Specialists); Jon K. Sekiya, MD (University of Michigan); Kevin G. Shea, MD (Intermountain Orthopedics); Orrin H. Sherman, MD (NYU Hospital for Joint Diseases); James R. Slauterbeck, MD (University of Vermont College of Medicine); Matthew V. Smith, MD (Washington University, St Louis); Jeffrey T. Spang, MD (University of North Carolina Medical Center); LTC Steven J. Svoboda, MD (Keller Army Community Hospital-United States Military Academy); Timothy N. Taft, MD (University of North Carolina Medical Center); Joachim J. Tenuta, MD (Albany Medical Center); Edwin M. Tingstad, MD (Inland Orthopaedics/Washington State University); Armando F. Vidal, MD (University of Colorado Denver School of Medicine); Darius G. Viskontas, MD (Royal Columbian Hospital); Richard A. White, MD (University of Missouri-Columbia); James S. Williams Jr, MD (Cleveland Clinic); Michelle L. Wolcott, MD (University of Colorado Denver School of Medicine); Brian R. Wolf, MD (University of Iowa Hospitals and Clinics); James J. York, MD (Chesapeake Orthopaedics \& Sports Medicine Center) 
determine if the prevalence, location and/or degree of meniscal and chondral damage noted at the time of revision ACL reconstruction predicts activity level, sports function, and osteoarthritis symptoms at two-year follow-up.

Hypothesis-The hypothesis is that meniscal loss and high grade chondral damage noted at the time of revision ACL reconstruction will result in lower activity levels, decreased sports participation, more pain, more stiffness and more functional limitation at two years following revision surgery.

Study Design-Cohort Study; Level of evidence, 2.

Methods-Between 2006 and 2011, 1205 patients who underwent revision ACL reconstruction by 83 surgeons at 52 hospitals were accumulated for study of the relationship of meniscal pathology and articular cartilage pathology to outcome. Baseline demographic and intraoperative data, including the IKDC subjective knee evaluation, KOOS, WOMAC and Marx activity score were collected initially and at two years follow-up to test the hypothesis.

Regression analysis was used to control for age, gender, body mass index, smoking status, activity level, baseline outcome scores, revision number, time since last ACL reconstruction, incidence of having a previous ACL reconstruction on the contralateral knee, previous and current meniscal and articular cartilage pathology, graft choice, and surgeon years of experience, in order to assess the meniscal and articular cartilage pathology risk factors for clinical outcomes two years after revision ACL reconstruction.

Results-At two years follow-up 82\% (989/1205) of the patients returned their questionnaires. It was found that previous meniscal pathology and current articular cartilage pathology were associated with the poorest outcomes, with prior lateral meniscectomy and current grade III-IV trochlear articular cartilage changes having the worst outcome scores. Activity levels at two years were not affected by meniscal or articular cartilage pathology.

Conclusions-Prior lateral meniscectomy and current grade III-IV changes of the trochlea are associated with worse outcomes in terms of decreased sports participation, more pain, more stiffness and more functional limitation at two years following revision surgery, but had no effect on activity levels.

Clinical Relevance-This study emphasizes the importance of the lateral meniscus, particularly in the presence of an ACL injury. Preservation of this structure should be one of the highest priorities during reconstructive surgery. Grade III-IV changes in the trochlea also has severe detrimental effects on the outcome of revision ACL reconstruction and measures need to be employed to prevent conditions that bring out deterioration of the trochlear cartilage.

\section{Keywords}

anterior cruciate ligament; revision ACL reconstruction; meniscus; articular cartilage; chondrosis; predictors; outcomes

\section{INTRODUCTION}

The outcome of revision anterior cruciate ligament (ACL) reconstruction has been reported in the literature to be inferior to that of primary ACL reconstructions, ${ }^{1,9,12,20,30,36,37}$ 
although the reasons behind this are varied. The recurrent injury and instability cause more trauma to the joint but it is unknown if specific joint injuries are associated with poorer results. The presence and severity of meniscal and/or chondral pathology have the potential to influence these outcomes. Previous literature has reported both an increased risk of subsequent posttraumatic osteoarthritis $2,5,18,22,23,28,38$ as well as poorer outcomes with the presence of these concomitant injuries at the time of primary ACL

reconstruction. $5,6,13,19,24,29,31,32,38$ However, the impact of meniscal and chondral damage on revision ACL reconstruction outcomes has not been previously definitively determined with high level evidence. ${ }^{15,33}$

There have been numerous publications on revision ACL reconstruction that have reported a high incidence of meniscal and chondral lesions at the time of revision surgery, with ranges reported between 36-75\% for meniscal pathology and 24-67\% for chondral pathology. ${ }^{14,15,21,25,27,33,35}$ These were more frequently identified than in the typical primary ACL reconstruction setting. ${ }^{34,37}$

The $\underline{S t u d y}$ Group investigated the association between previous meniscal surgery and the presence of chondral lesions at the time of revision ACL reconstruction. ${ }^{4}$ The group found that the articular cartilage condition noted at the time of revision surgery related to previous meniscal surgery, independent of the effect of patient's age. ${ }^{4}$ In addition, previous partial meniscectomy was associated with a higher incidence of articular cartilage lesions, whereas previous meniscal repair was not. However, the Brophy et al MARS study only looked at pathology at the time of revision surgery, and did not investigate if meniscal and chondral damage predicted patient outcomes following the revision.

The goal of the present study was to determine if specific meniscal and/or chondral damage noted at the time of revision ACL reconstruction can be predictive of patient reported activity level, sports function and osteoarthritic symptoms at two-year follow-up. It was hypothesized that the incidence of meniscus pathology and high grade articular cartilage pathology portends a worse outcome as measured by patient reported outcomes using the IKDC, Marx, KOOS and WOMAC scoring instruments two years following revision ACL reconstruction. If so, strategies could be developed by surgeons to improve these outcomes by modifying the management of meniscal and chondral injuries in the future.

\section{MATERIALS AND METHODS}

\section{Study Design}

The $\underline{\text { Study }}$ Group was assembled with the aim of determining what impacts outcome in an ACL revision setting, and to identify potentially modifiable factors that could improve these outcomes. ${ }^{16,17}$ This collaboration consists of a group of 83 sports medicine fellowship trained surgeons at 52 sites. Surgeons are a mix of academic $(n=23 ; 44 \%)$ and private practitioners $(\mathrm{n}=29 ; 56 \%)$. Surgeon inclusion criteria included maintenance of an active Institutional Review Board (IRB) approval, completion of a training session that integrated articular cartilage and meniscus agreement studies, review of the study design and patient inclusion criteria, and a review of the surgeon questionnaire. Surgeons performed the ACL revision surgery according to their own practice preferences. 


\section{Study Population}

After IRB approval from each institution, 1205 patients with documented ACL reconstruction failure who underwent revision ACL reconstruction surgery qualified for and agreed to be included in this study. This multicenter consortium began patient enrollment in 2006 and ended in 2011. Study inclusion criteria were all ACL deficient candidates presenting to the clinic between the ages of 12 and 65 that were scheduled to have a revision ACL reconstruction by a participating (MARS Study) surgeon. All participants were required to have undergone a prior ACL reconstruction and had failure of their ACL reconstruction, as defined by the surgeon by either MRI, knee laxity (KT $>5 \mathrm{~mm}$ ), a positive pivot shift or Lachman's, functional instability, and/or by arthroscopic confirmation. ACL deficient patients with concomitant injuries to the collateral ligaments (MCL, LCL), PCL, or posterolateral complex were included, but subsequently excluded from the analysis for this study. Exclusion criteria were patients presenting to the clinic with prior infection, arthrofibrosis, or complex regional pain syndrome. Patients unwilling or unable to complete their repeat questionnaire two years after their initial visit are also excluded.

\section{Data Sources and Measurement}

After obtaining informed consent, the patient filled out a 13-page questionnaire that included questions regarding demographics, sports participation, injury mechanism, comorbidities and knee injury history. Within this questionnaire, each participant also completed a series of validated general and knee-specific outcome instruments, including the Knee Injury and Osteoarthritis Outcome Score (KOOS), the International Knee Documentation Committee Subjective form (IKDC) and the Marx activity rating scale. Contained within the KOOS was the Western Ontario and McMaster Universities Osteoarthritis Index (WOMAC). Surgeons filled out a questionnaire that included the impression of the etiology of the previous ACL reconstruction failure, physical exam findings, surgical technique utilized and the intraarticular findings and surgical management of meniscal and chondral damage. Chondral damage was described using the modified Outerbridge system ${ }^{7}$ with 'worse grade' defined in this study as being a grade II or higher. Meniscus injuries were classified by location, partial versus complete tears, while treatment was recorded as no treatment, repair, resection, or other (ie. abrade + trephine, meniscal transplant, etc). For the purposes of this study, "previous" or "prior" refers to meniscal or articular cartilage injuries documented prior to the time of the ACL revision surgery. This was determined either by previous operative reports or by noting surgical changes consistent with previous meniscal resection. "Current" refers to meniscal or articular cartilage damage noted for the first time at ACL revision surgery.

\section{Patient Follow-up}

Two-year patient follow-up was completed by mail with re-administration of the same questionnaire as the one they completed at baseline. Patients were also contacted by phone to determine whether any subsequent surgery had occurred to either knee since their initial revision ACL reconstruction. If so, operative reports were obtained, whenever possible, in order to verify pathology and treatment. 


\section{Statistical Analysis}

To describe our patient sample, we summarized continuous variables as percentiles (i.e., $25^{\text {th }}, 50^{\text {th }}$, and $\left.75^{\text {th }}\right)$, and categorical variables with frequencies and percentages.

Multivariable regression analyses were constructed to examine which baseline risk factors were independently associated with each outcome variable. The primary outcome variables of interest were the two-year outcome scores of the KOOS, IKDC, WOMAC and Marx activity level. These primary outcome variables were all treated as continuous. The covariates that we controlled for were age, gender, body mass index, smoking status, baseline activity level, baseline outcome scores, revision number, time since last ACL reconstruction, incidence of having a previous ACL reconstruction on the contralateral knee, previous and current meniscal and articular cartilage pathology, graft choice, and surgeon years of experience, in order to assess the meniscal and articular cartilage pathology risk factors for clinical outcomes two years after revision ACL reconstruction. Due to the low frequency counts of grade IV articular cartilage pathology in the medial tibial plateau, lateral tibial plateau, patella and trochlear compartments, these grades were combined with their respective grade III compartment pathology to form a combined "grades 3-4" variable for each of these four compartments for analysis purposes. Statistical analysis was performed using open source R statistical software (www.r-project.org; Version 3.0.3).

\section{RESULTS}

A total of 1205 patients met the inclusion criteria and were enrolled in the study. Table 1 summarizes the baseline characteristics of the cohort, which consisted of 697 (58\%) males and a median cohort age of 26 years (range: 12-63). The median time since their last ACL reconstruction was 3.4 years. The surgeons noted previous pathology and treatment of the medial meniscus (38\%), lateral meniscus (20\%), and articular surfaces (12\%) at the time of revision surgery as ascertained by direct observation and previous history and operative notes. The surgeons also reported current pathology in the medial meniscus (45\%), lateral meniscus (37\%), medial femoral condyle (43\%), lateral femoral condyle (29\%), medial tibial plateau (11\%), lateral tibial plateau (17\%), patella (30\%), and trochlea (20\%). Patients in the cohort were noted to have either current or previous meniscus pathology and/or grade II or greater articular cartilage pathology $91 \%$ of the time (Table 2). Fifty-nine percent (59\%) of patients were noted to have both meniscus and articular cartilage pathology. Only 9\% (114/1205) of the patients had neither meniscus nor articular cartilage pathology at the time of revision ACL reconstruction.

At two years, follow-up was obtained on 82\% (989/1205). Previous medial and lateral meniscal pathology and treatment, as well as current articular cartilage pathology (all surfaces except for the lateral femoral condyle) were found to be significantly associated with poorer outcomes at two years following revision ACL reconstruction (Table 3). The most consistent cartilage-related factors driving outcome in revision patients were previous lateral meniscus pathology and current trochlea articular cartilage pathology. Having a previous partial meniscectomy of the lateral meniscus resulted in significantly poorer outcomes on the IKDC (odds ratio $[\mathrm{OR}]=1.69 ; 95 \% \mathrm{CI}=1.16-2.44 ; \mathrm{p}=0.005$ ), all KOOS subscales $(\mathrm{OR}$ range $=1.52-2.08 ; 95 \% \mathrm{CI}=1.04-3.03 ; \mathrm{p}<0.03)$, and all WOMAC subscales 
$(\mathrm{OR}=1.56 ; 95 \% \mathrm{CI}=1.06-2.27 ; \mathrm{p}<0.03)$. Having a current Grade III-IV articular cartilage chondrosis of the trochlea resulted in significantly poorer outcomes in the IKDC (OR=1.89; 95\% $\mathrm{CI}=1.25-2.86$; $\mathrm{p}=0.003$ ), 4 of 5 KOOS subscales (OR range $=1.64-2.70$; 95\% $\mathrm{CI}=1.09-$ 4.17; $\mathrm{p}<0.02$ ), and 2 of 3 WOMAC subscales (OR range $=1.61-2.70 ; 95 \% \mathrm{CI}=1.04-4.17$; $\mathrm{p} \unlhd(03)$.

Lower baseline outcome scores, lower baseline activity level, and shorter time interval between the patient's last ACL reconstruction and the ACL revision surgery also significantly increased the odds of reporting poorer clinical outcomes at two years (Table 4).

Interestingly, the degree of previous and current meniscal and articular cartilage damage associated with ACL revision surgery did not predict Marx activity levels at two years (Table 3). However, a variety of other factors were found to significantly influence decreased two year activity level: lower baseline activity level, older age, female gender, being a current smoker at baseline, and having a previous ACL reconstruction on the contralateral knee (Table 4).

\section{DISCUSSION}

The current study supports our hypothesis that patient reported outcomes at two years are impacted by both articular cartilage and meniscus pathology. The most significant impact on outcomes at two years was when there was a previous lateral menisectomy or high grade trochlear groove articular cartilage pathology. Both produced consistently worse outcomes for the IKDC, KOOS and WOMAC subscales at two year follow-up, compared to patients without this pathology. Subjects with previous partial lateral meniscectomies were 1.5-2.1 times more likely to have a significantly poorer clinical outcome at two years following their revision surgery compared to those without previous partial lateral meniscectomy, whereas subjects who had high grade trochlear groove articular cartilage pathology were found to be 1.6-2.7 times more likely to report significantly poorer two year outcomes.

Previous studies have found, similar to the current study, a significant amount of articular cartilage and/or meniscus pathology at the time of revision ACL reconstruction. $8,11,33$ Garafolo et al noted $32 \%$ of patients had Grade II or worse articular cartilage changes and $39 \%$ had meniscus tears at the time of revision ACL reconstruction. ${ }^{11}$ Diamantopoulos et al in a study involving 107 revision patients, noted that $61.7 \%$ of patients had Grade II or worse articular cartilage changes at the time of revision. ${ }^{8}$ In 2012, Wright et al performed a mixed-effect-model meta-analysis of the results of revision ACL reconstruction. ${ }^{37}$ It was noted that patients within studies where meniscus and articular cartilage pathology was reported, $42 \%$ had undergone treatment of a meniscus tear at the time of their primary ACL reconstruction and 38\% underwent meniscus treatment at the time of revision ACL reconstruction. ${ }^{37}$ Sixty-four percent $(64 \%)$ of the time in patients undergoing revision ACL reconstruction, meniscal treatment involved the medial meniscus. Grade I articular cartilage pathology was noted in $34.1 \%$ of patients undergoing revision ACL reconstruction, Grade II in $44.8 \%$, Grade III in $17.6 \%$, and Grade IV in $3.4 \%$. The anatomical location of the articular cartilage pathology included medial compartment (29.1\%), lateral compartment (37.5\%), and patellofemoral (33.3\%). Fox et al in their series of patellar tendon allograft for 
revision ACL reconstructions noted 70\% of patients had articular cartilage pathology in at least one of the three compartments. ${ }^{10}$ In the present study which employed an equal number of autografts and allografts, $78 \%$ of patients exhibited abnormal meniscal pathology at the time of revision, while $72 \%$ exhibited chondral pathology in at least one of the three compartments. Remarkably, only $9 \%$ of the cohort had normal meniscal and chondral surfaces at the time of revision.

The early portion of the $\underline{S t u d y}$ cohort utilizing similar prospective collection methods for primary and revision ACL reconstructions demonstrated that revision ACL reconstructions had a significantly higher incidence of articular cartilage pathology compared with primary ACL reconstructions. ${ }^{3}$ There was an increased risk of Grade III and IV articular cartilage changes in the lateral compartment (odds ratio 1.73) and trochlear groove-patellofemoral compartment (odds ratio 1.70) in the revision setting as compared to primary ACL reconstructions.

Previous studies have suggested that meniscal and articular cartilage pathology may be proportional to the delay between ACL graft re-tear and revision ACL reconstruction. ${ }^{4,27}$ Ohly et al noted that in the early group who had revision ACL reconstruction within 6 months of graft failure had $76 \%$ normal articular cartilage as compared to $46.8 \%$ in the delayed revision ACL reconstruction group. ${ }^{27}$ In the current study it is difficult to ascertain the time of failure. Many patients have an insidious failure of their graft and cannot identify the exact moment that ACL graft failure occurred. Thus, while it seems intuitive that instability episodes and prolonged delay prior to revision ACL reconstruction may increase the risk of meniscus and articular cartilage pathology, this was unable to be accurately assessed in the present study.

Noyes and Westin, in a series of revision ACL reconstructions performed with quadriceps tendon-patellar bone autograft, found that $93 \%$ had pathology in addition to the ACL graft rupture, including $56 \%$ that had articular cartilage pathology that resulted in decreased ability to return to sports activity. ${ }^{26}$ Additionally, they concluded that the patients with varus malalignment should undergo high tibial osteotomy based on improved results in their cohort.

Articular cartilage pathology has been previously noted in revision ACL reconstructions and has been presumed to be associated with worse patient reported outcomes. ${ }^{20}$ In results from the Swedish National Register, Kvist et al noted that all KOOS subscales were lower in revision patients versus primary ACL reconstructions. The present study also found worse patient reported outcomes in revision ACL reconstruction when compared to results usually seen in primary ACL reconstruction patients.

In a previous study by the MARS Study Group an association was demonstrated between previous meniscectomy during prior ACL reconstruction and articular cartilage chondrosis at the time of revision ACL reconstruction. ${ }^{4}$ In that study previous partial meniscectomy at the time of ACL reconstruction produced significantly more articular cartilage pathology when compared to when a normal meniscus was found or a meniscus repair was performed at the time of ACL reconstruction. The latter work demonstrates the importance of 
preserving meniscal tissue whenever possible and emphasizes the need for new and improved meniscus salvage techniques. We believe this is related to the observation in the current study that previous lateral meniscectomy is a stronger predictor for worse outcome than a meniscal tear treated at the time of revision ACL reconstruction. The patient has had a longer exposure to the deleterious effects of meniscus loss.

The reason for the large effect that trochlear groove chondrosis has on outcome compared with similar grades of chondrosis involving the tibial plateau or femoral condyle is uncertain. It may be that patellofemoral articular cartilage damage has a larger impact on activity performance than previous studies have been capable of demonstrating or measuring. The MARS group will continue to monitor these findings in subsequent followup studies.

The use of validated patient outcomes in the current multicenter, large, carefully documented, prospective case study provides reliable information about what results can be expected from revision ACL reconstruction that was not previously available. This data has great value for the practicing orthopedic surgeon, providing more accurate patient counseling with regards to their predicted outcome following revision ACL reconstruction.

Strengths of this study include the large cohort and the ability to do multivariable analysis given the number of patients with high follow-up at two years. The consistent use of validated patient reported outcomes remains a strength of the cohort. Additionally the geographic variability along with the variability of academic and private practice surgeons makes the results generalizable. Weaknesses of the study include short two year follow-up and the lack of onsite follow-up and follow-up imaging.

\section{CONCLUSIONS}

Revision ACL reconstruction patients with prior partial lateral meniscectomy and revision ACL reconstruction patients with current grade III-IV articular cartilage damage to the trochlear groove scored significantly lower at two years on the IKDC, KOOS and WOMAC questionnaires than revision ACL reconstruction patients with other injuries. The result of this study support the aggressive preservation of the lateral meniscus at the time of primary ACL reconstruction and the use of preventative and restorative techniques to preserve the integrity of the trochlear articular cartilage at the time of ACL reconstruction and revision ACL reconstruction. Improved management of these findings both prior to and at the time of revision ACL reconstruction may be surgeon modifiable factors that would improve patient outcomes.

\section{Bibliography}

1. Ahlden M, Samuelsson K, Sernert N, Forssblad M, Karlsson J, Kartus J. The Swedish National Anterior Cruciate Ligament Register: A Report on Baseline Variables and Outcomes of Surgery for Almost 18,000 Patients. Am J Sports Med. 2012; 40(10):2230-2235. [PubMed: 22962296]

2. Barenius B, Ponzer S, Shalabi A, Bujak R, Norlen L, Eriksson K. Increased Risk of Osteoarthritis after Anterior Cruciate Ligament Reconstruction: A 14-Year Follow-up Study of a Randomized Controlled Trial. Am J Sports Med. 2014; 42(5):1049-1057. [PubMed: 24644301] 
3. Borchers JR, Kaeding CC, Pedroza AD, et al. Intra-Articular Findings in Primary and Revision Anterior Cruciate Ligament Reconstruction Surgery: A Comparison of the Moon and Mars Study Groups. Am J Sports Med. 2011; 39(9):1889-1893. [PubMed: 21646434]

4. Brophy RH, Wright RW, David TS, et al. Association between Previous Meniscal Surgery and the Incidence of Chondral Lesions at Revision Anterior Cruciate Ligament Reconstruction. Am J Sports Med. 2012; 40(4):808-814. [PubMed: 22374942]

5. Cohen M, Amaro JT, Ejnisman B, et al. Anterior Cruciate Ligament Reconstruction after 10 to 15 Years: Association between Meniscectomy and Osteoarthrosis. Arthroscopy. 2007; 23(6):629-634. [PubMed: 17560477]

6. Cox CL, Huston LJ, Dunn WR, et al. Are Articular Cartilage Lesions and Meniscus Tears Predictive of Ikdc, Koos, and Marx Activity Level Outcomes after Anterior Cruciate Ligament Reconstruction? A 6-Year Multicenter Cohort Study. Am J Sports Med. 2014; 42(5):1058-1067. [PubMed: 24647881]

7. Curl WW, Krome J, Gordon ES, Rushing J, Smith BP, Poehling GG. Cartilage Injuries: A Review of 31,516 Knee Arthroscopies. Arthroscopy. 1997; 13(4):456-460. [PubMed: 9276052]

8. Diamantopoulos AP, Lorbach O, Paessler HH. Anterior Cruciate Ligament Revision Reconstruction: Results in 107 Patients. Am J Sports Med. 2008; 36(5):851-860. [PubMed: 18272793]

9. Filbay SR, Ackerman IN, Russell TG, Macri EM, Crossley KM. Health-Related Quality of Life after Anterior Cruciate Ligament Reconstruction: A Systematic Review. Am J Sports Med. 2014; 42(5):1247-1255. [PubMed: 24318609]

10. Fox JA, Pierce M, Bojchuk J, Hayden J, Bush-Joseph CA, Bach BR Jr. Revision Anterior Cruciate Ligament Reconstruction with Nonirradiated Fresh-Frozen Patellar Tendon Allograft. Arthroscopy. 2004; 20(8):787-794. [PubMed: 15483538]

11. Garofalo R, Djahangiri A, Siegrist O. Revision Anterior Cruciate Ligament Reconstruction with Quadriceps Tendon-Patellar Bone Autograft. Arthroscopy. 2006; 22(2):205-214. [PubMed: 16458807]

12. George MS, Dunn WR, Spindler KP. Current Concepts Review: Revision Anterior Cruciate Ligament Reconstruction. Am J Sports Med. 2006; 34(12):2026-2037. [PubMed: 17092921]

13. Gerhard P, Bolt R, Duck K, Mayer R, Friederich NF, Hirschmann MT. Long-Term Results of Arthroscopically Assisted Anatomical Single-Bundle Anterior Cruciate Ligament Reconstruction Using Patellar Tendon Autograft: Are There Any Predictors for the Development of Osteoarthritis? Knee Surg Sports Traumatol Arthrosc. 2013; 21(4):957-964. [PubMed: 22488015]

14. Granan LP, Inacio MC, Maletis GB, Funahashi TT, Engebretsen L. Intraoperative Findings and Procedures in Culturally and Geographically Different Patient and Surgeon Populations: An Anterior Cruciate Ligament Reconstruction Registry Comparison between Norway and the USA. Acta Orthop. 2012; 83(6):577-582. [PubMed: 23116436]

15. Griffith TB, Allen BJ, Levy BA, Stuart MJ, Dahm DL. Outcomes of Repeat Revision Anterior Cruciate Ligament Reconstruction. Am J Sports Med. 2013; 41(6):1296-1301. [PubMed: 23605223]

16. Group M, Group M. Effect of Graft Choice on the Outcome of Revision Anterior Cruciate Ligament Reconstruction in the Multicenter Acl Revision Study (Mars) Cohort. Am J Sports Med. 2014; 42(10):2301-2310. [PubMed: 25274353]

17. Group M. Wright RW, Huston LJ, et al. Descriptive Epidemiology of the Multicenter Acl Revision Study (Mars) Cohort. Am J Sports Med. 2010; 38(10):1979-1986. [PubMed: 20889962]

18. Ichiba A, Kishimoto I. Effects of Articular Cartilage and Meniscus Injuries at the Time of Surgery on Osteoarthritic Changes after Anterior Cruciate Ligament Reconstruction in Patients under 40 Years Old. Arch Orthop Trauma Surg. 2009; 129(3):409-415. [PubMed: 19050905]

19. Kartus JT, Russell VJ, Salmon LJ, et al. Concomitant Partial Meniscectomy Worsens Outcome after Arthroscopic Anterior Cruciate Ligament Reconstruction. Acta Orthop Scand. 2002; 73(2): 179-185. [PubMed: 12079016]

20. Kvist J, Kartus J, Karlsson J, Forssblad M. Results from the Swedish National Anterior Cruciate Ligament Register. Arthroscopy. 2014; 30(7):803-810. [PubMed: 24746404] 
21. Leroux T, Wasserstein D, Dwyer T, et al. The Epidemiology of Revision Anterior Cruciate Ligament Reconstruction in Ontario, Canada. Am J Sports Med. 2014; 42(11):2666-2672. [PubMed: 25214531]

22. Magnussen RA, Mansour AA, Carey JL, Spindler KP. Meniscus Status at Anterior Cruciate Ligament Reconstruction Associated with Radiographic Signs of Osteoarthritis at 5- to 10-Year Follow-Up: A Systematic Review. J Knee Surg. 2009; 22(4):347-357. [PubMed: 19902731]

23. Magnussen RA, Spindler KP. The Effect of Patient and Injury Factors on Long-Term Outcome after Anterior Cruciate Ligament Reconstruction. Curr Orthop Pract. 2011; 22(1):90-103. [PubMed: 24772230]

24. McAllister DR, Foster B, Martin DE, et al. Outcome of Chronic Isolated Anterior Cruciate Ligament Reconstruction. J Knee Surg. 2014; 27(5):383-392. [PubMed: 24443288]

25. Noyes FR, Barber-Westin SD. Anterior Cruciate Ligament Revision Reconstruction: Results Using a Quadriceps Tendon-Patellar Bone Autograft. Am J Sports Med. 2006; 34(4):553-564. [PubMed: 16365373]

26. Noyes FR, Barber-Westin SD. Revision Anterior Cruciate Ligament Reconstruction: Report of 11Year Experience and Results in 114 Consecutive Patients. Instr Course Lect. 2001; 50:451-461. [PubMed: 11372346]

27. Ohly NE, Murray IR, Keating JF. Revision Anterior Cruciate Ligament Reconstruction: Timing of Surgery and the Incidence of Meniscal Tears and Degenerative Change. J Bone Joint Surg Br. 2007; 89(8):1051-1054. [PubMed: 17785744]

28. Oiestad BE, Holm I, Aune AK, et al. Knee Function and Prevalence of Knee Osteoarthritis after Anterior Cruciate Ligament Reconstruction: A Prospective Study with 10 to 15 Years of FollowUp. Am J Sports Med. 2010; 38(11):2201-2210. [PubMed: 20713644]

29. Rotterud JH, Sivertsen EA, Forssblad M, Engebretsen L, Aroen A. Effect of Meniscal and Focal Cartilage Lesions on Patient-Reported Outcome after Anterior Cruciate Ligament Reconstruction: A Nationwide Cohort Study from Norway and Sweden of 8476 Patients with 2-Year Follow-Up. Am J Sports Med. 2013; 41(3):535-543. [PubMed: 23371474]

30. Salmon LJ, Pinczewski LA, Russell VJ, Refshauge K. Revision Anterior Cruciate Ligament Reconstruction with Hamstring Tendon Autograft: 5- to 9-Year Follow-Up. Am J Sports Med. 2006; 34(10):1604-1614. [PubMed: 16685086]

31. Shelbourne KD, Gray T. Results of Anterior Cruciate Ligament Reconstruction Based on Meniscus and Articular Cartilage Status at the Time of Surgery. Five- to Fifteen-Year Evaluations. Am J Sports Med. 2000; 28(4):446-452. [PubMed: 10921633]

32. Sofu H, Yildirim T, Gursu S, Issin A, Sahin V. Short-Term Effects of Partial Meniscectomy on the Clinical Results of Anterior Cruciate Ligament Reconstruction. Knee Surg Sports Traumatol Arthrosc. 2015; 23(1):184-187. [PubMed: 24682517]

33. Trojani C, Sbihi A, Djian P, et al. Causes for Failure of Acl Reconstruction and Influence of Meniscectomies after Revision. Knee Surg Sports Traumatol Arthrosc. 2011; 19(2):196-201. [PubMed: 20644911]

34. Wegrzyn J, Chouteau J, Philippot R, Fessy MH, Moyen B. Repeat Revision of Anterior Cruciate Ligament Reconstruction: A Retrospective Review of Management and Outcome of 10 Patients with an Average 3-Year Follow-Up. Am J Sports Med. 2009; 37(4):776-785. [PubMed: 19336620]

35. Widener DB, Wilson DJ, Galvin JW, Marchant BG, Arrington ED. The Prevalence of Meniscal Tears in Young Athletes Undergoing Revision Anterior Cruciate Ligament Reconstruction. Arthroscopy. 2014

36. Wright RW, Dunn WR, Amendola A, et al. Anterior Cruciate Ligament Revision Reconstruction: Two-Year Results from the Moon Cohort. J Knee Surg. 2007; 20(4):308-311. [PubMed: 17993075]

37. Wright RW, Gill CS, Chen L, et al. Outcome of Revision Anterior Cruciate Ligament Reconstruction: A Systematic Review. J Bone Joint Surg Am. 2012; 94(6):531-536. [PubMed: 22438002]

38. Wu WH, Hackett T, Richmond JC. Effects of Meniscal and Articular Surface Status on Knee Stability, Function, and Symptoms after Anterior Cruciate Ligament Reconstruction: A Long-Term Prospective Study. Am J Sports Med. 2002; 30(6):845-850. [PubMed: 12435651] 


\section{What is known about the subject}

Articular cartilage and meniscus pathology is common in the revision ACL setting and more common than that found in primary ACL reconstructions. The impact of this in contributing to worse outcomes is not known. Little prospective evidence utilizing validated patient reported outcomes exists to provide patients with appropriate expectations for their eventual outcomes.

\section{Adds to existing knowledge}

This study provides evidence from a prospective cohort that previous meniscectomy prior to revision and current articular cartilage damage predict worse outcomes as measured by patient reported outcome measures. 
Table 1

Baseline Characteristics of Overall Cohort and the Patients Lost to Follow-up

\begin{tabular}{|c|c|c|}
\hline & $\begin{array}{l}\text { Overall Cohort } \\
(\mathrm{N}=1205)\end{array}$ & $\begin{array}{l}\text { Lost to follow-up @ } 2 \text { years } \\
(\mathrm{N}=219)\end{array}$ \\
\hline \multicolumn{3}{|l|}{ Patient Demographics } \\
\hline \multicolumn{3}{|l|}{ Gender } \\
\hline •Males & $697(58 \%)$ & $152(69 \%)$ \\
\hline •Females & $508(42 \%)$ & $67(31 \%)$ \\
\hline Age (years) & $26(20,34)$ & $25(20,33)$ \\
\hline Body Mass Index & $25.1(22.6,28.5)$ & $26.3(23.1,30.5)$ \\
\hline Baseline Activity Level (range, 0-16) & $11(4,16)$ & $9(3,14)$ \\
\hline \multicolumn{3}{|l|}{ Smoking Status } \\
\hline •Never & $923(77 \%)$ & $156(71 \%)$ \\
\hline •Quit & $154(13 \%)$ & $32(15 \%)$ \\
\hline •Current & $109(9 \%)$ & $25(11 \%)$ \\
\hline \multicolumn{3}{|l|}{ Previous Surgical Information } \\
\hline Time since last ACL reconstruction (years) & $3.4(1.4,8.3)$ & $2.9(1.4,6.3)$ \\
\hline \multicolumn{3}{|l|}{ Revision Number } \\
\hline$\bullet 1$ & $1055(88 \%)$ & $184(84 \%)$ \\
\hline$\cdot 2$ & $125(10 \%)$ & $29(13 \%)$ \\
\hline$\cdot 3$ or more & $25(2 \%)$ & $6(3 \%)$ \\
\hline \multicolumn{3}{|l|}{ Previous Medial Meniscus Surgery } \\
\hline$\cdot$ No & $743(62 \%)$ & $125(57 \%)$ \\
\hline •Yes, repair healed/stable & $31(3 \%)$ & $5(2 \%)$ \\
\hline •Yes, repair not healed/unstable & $68(6 \%)$ & $19(9 \%)$ \\
\hline •Yes, excision & $362(30 \%)$ & $69(32 \%)$ \\
\hline \multicolumn{3}{|l|}{ Previous Lateral Meniscus Surgery } \\
\hline$\cdot$ No & $958(80 \%)$ & $156(71 \%)$ \\
\hline •Yes, repair healed/stable & $28(2 \%)$ & $7(3 \%)$ \\
\hline •Yes, repair not healed/unstable & $23(2 \%)$ & $6(3 \%)$ \\
\hline •Yes, excision & $195(16 \%)$ & $49(22 \%)$ \\
\hline \multicolumn{3}{|l|}{ Previous Articular Cartilage Surgeries } \\
\hline$\cdot$ No & $1059(88 \%)$ & $186(85 \%)$ \\
\hline •Yes & $146(12 \%)$ & $33(15 \%)$ \\
\hline \multicolumn{3}{|c|}{ Previous ACL Reconstruction on Contralateral Knee } \\
\hline$\cdot$ No & $1083(90 \%)$ & $203(93 \%)$ \\
\hline •Yes & $122(10 \%)$ & $16(7 \%)$ \\
\hline \multicolumn{3}{|l|}{ Current Surgical Information } \\
\hline \multicolumn{3}{|l|}{ Current Graft Type } \\
\hline •Autograft - BTB & $336(28 \%)$ & $67(31 \%)$ \\
\hline
\end{tabular}




\begin{tabular}{|c|c|c|}
\hline & $\begin{array}{c}\text { Overall Cohort } \\
(\mathrm{N}=1205)\end{array}$ & $\begin{array}{c}\text { Lost to follow-up @ } 2 \text { years } \\
(\mathrm{N}=219)\end{array}$ \\
\hline -Autograft - soft tissue & $244(20 \%)$ & $37(17 \%)$ \\
\hline •Allograft - BTB & $286(24 \%)$ & $49(22 \%)$ \\
\hline -Allograft - soft tissue & $298(25 \%)$ & $57(26 \%)$ \\
\hline -Other (ie. both autograft + allograft) & $39(3 \%)$ & $8(4 \%)$ \\
\hline Surgeon Experience (years) & $13(8,18)$ & $13(8,17)$ \\
\hline \multicolumn{3}{|l|}{ Current Meniscal Pathology } \\
\hline \multicolumn{3}{|l|}{ Medial } \\
\hline •Normal & $663(55 \%)$ & $121(55 \%)$ \\
\hline -No treatment for tear & $25(2 \%)$ & $2(1 \%)$ \\
\hline •Repair & $163(14 \%)$ & $36(16 \%)$ \\
\hline$\cdot$ Excision & $330(27 \%)$ & $49(22 \%)$ \\
\hline •Other & $24(2 \%)$ & $10(5 \%)$ \\
\hline \multicolumn{3}{|l|}{ Lateral } \\
\hline •Normal & $765(63 \%)$ & $134(61 \%)$ \\
\hline -No treatment for tear & $57(5 \%)$ & $9(4 \%)$ \\
\hline •Repair & $62(5 \%)$ & $13(6 \%)$ \\
\hline •Excision & $313(26 \%)$ & $58(27 \%)$ \\
\hline -Other & $8(1 \%)$ & $4(2 \%)$ \\
\hline
\end{tabular}

Current Articular Cartilage Pathology

\begin{tabular}{|c|c|c|}
\hline \multicolumn{3}{|l|}{ Medial Femoral Condyle } \\
\hline •Normal/Grade 1 & $682(57 \%)$ & $118(54 \%)$ \\
\hline • Grade 2 & $288(24 \%)$ & $56(26 \%)$ \\
\hline -Grade 3 & $164(14 \%)$ & $34(16 \%)$ \\
\hline •Grade 4 & $71(6 \%)$ & $10(5 \%)$ \\
\hline \multicolumn{3}{|l|}{ Lateral Femoral Condyle } \\
\hline •Normal/Grade 1 & $858(71 \%)$ & $149(68 \%)$ \\
\hline • Grade 2 & $187(16 \%)$ & $40(18 \%)$ \\
\hline •Grade 3 & $96(8 \%)$ & $18(8 \%)$ \\
\hline •Grade 4 & $64(5 \%)$ & $11(5 \%)$ \\
\hline \multicolumn{3}{|l|}{ Medial Tibial Plateau } \\
\hline •Normal/Grade 1 & $1075(89 \%)$ & $188(86 \%)$ \\
\hline -Grade 2 & $93(8 \%)$ & $24(11 \%)$ \\
\hline • Grade 3 & $21(2 \%)$ & $4(2 \%)$ \\
\hline • Grade 4 & $16(1 \%)$ & $2(1 \%)$ \\
\hline \multicolumn{3}{|l|}{ Lateral Tibial Plateau } \\
\hline •Normal/Grade 1 & $997(83 \%)$ & $174(80 \%)$ \\
\hline -Grade 2 & $156(13 \%)$ & $33(15 \%)$ \\
\hline • Grade 3 & $45(4 \%)$ & $9(4 \%)$ \\
\hline •Grade 4 & $7(<1 \%)$ & $2(1 \%)$ \\
\hline
\end{tabular}




\begin{tabular}{|c|c|c|}
\hline & $\begin{array}{c}\text { Overall Cohort } \\
(\mathrm{N}=1205)\end{array}$ & $\begin{array}{c}\text { Lost to follow-up @ } 2 \text { years } \\
(\mathrm{N}=219)\end{array}$ \\
\hline \multicolumn{3}{|l|}{ Patella } \\
\hline -Normal/Grade 1 & $843(70 \%)$ & $150(68 \%)$ \\
\hline - Grade 2 & $234(19 \%)$ & $45(21 \%)$ \\
\hline - Grade 3 & $119(10 \%)$ & $21(10 \%)$ \\
\hline -Grade 4 & $9(1 \%)$ & $2(1 \%)$ \\
\hline \multicolumn{3}{|l|}{ Trochlea } \\
\hline -Normal/Grade 1 & $959(80 \%)$ & $180(82 \%)$ \\
\hline - Grade 2 & $101(8 \%)$ & $11(5 \%)$ \\
\hline - Grade 3 & $90(7 \%)$ & $12(6 \%)$ \\
\hline -Grade 4 & $55(5 \%)$ & $15(7 \%)$ \\
\hline
\end{tabular}

Note: $\mathrm{n}(\%)$ of non-missing values

$\mathrm{a}(\mathrm{b}, \mathrm{c})$ represents the median $\mathrm{a}$, lower quartile $\mathrm{b}$, and the upper quartile $\mathrm{c}$ for continuous variables. 
Table 2

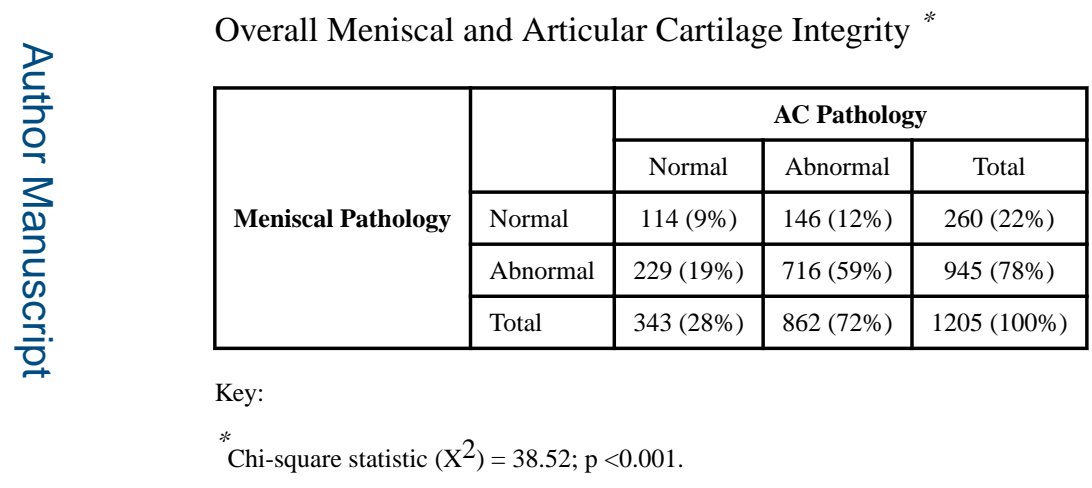




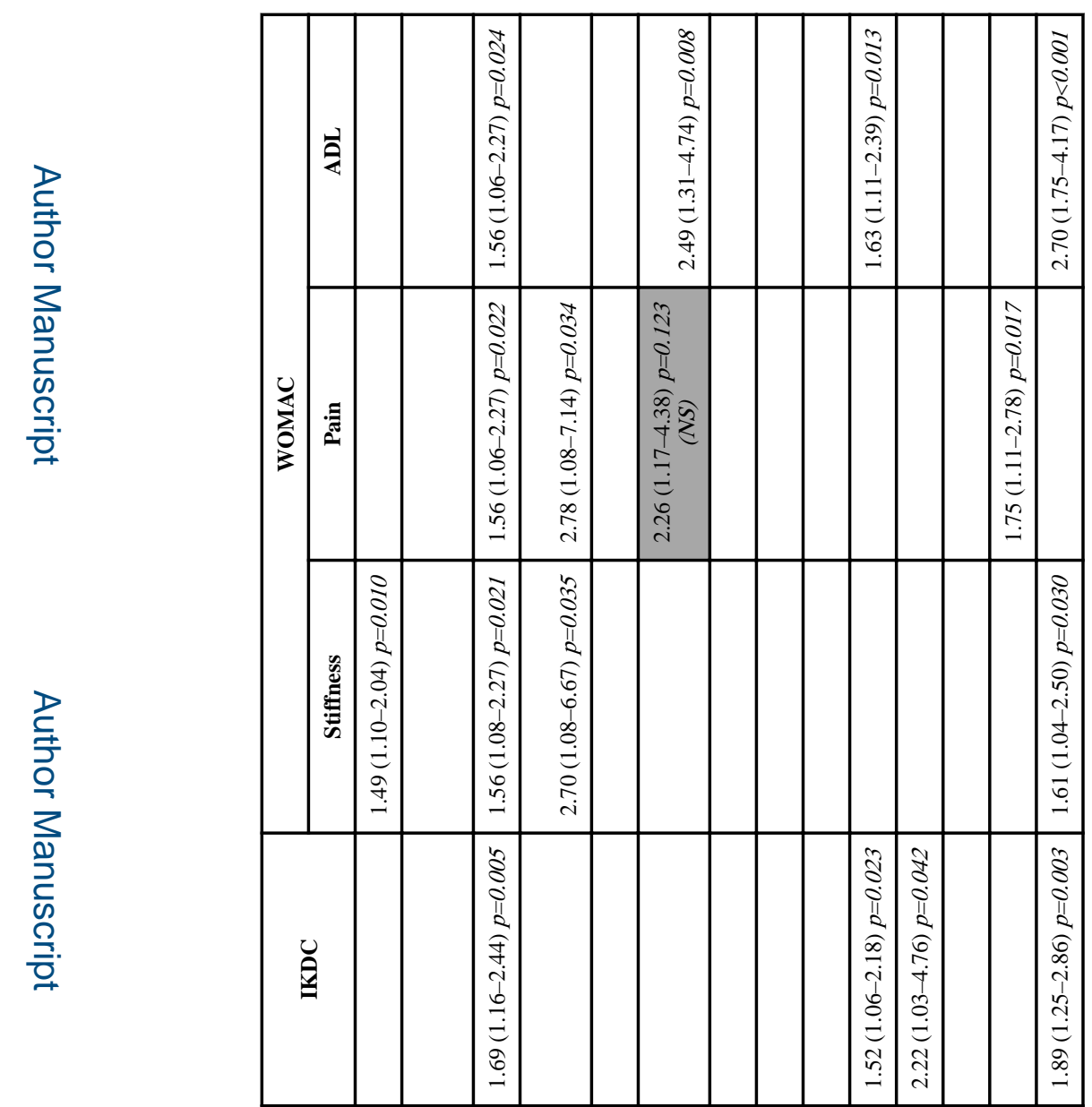

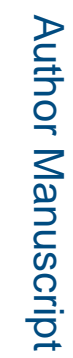

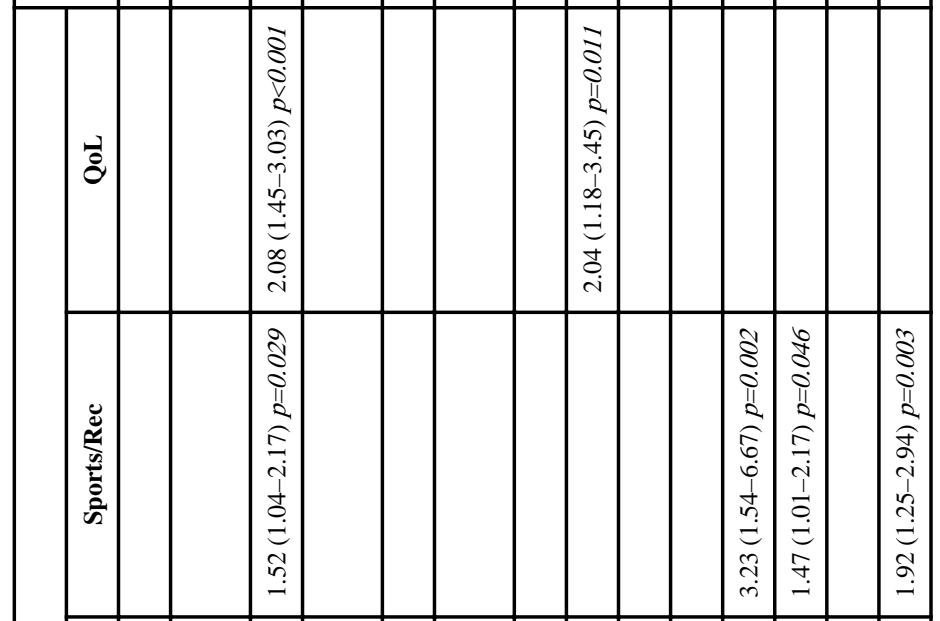

롤

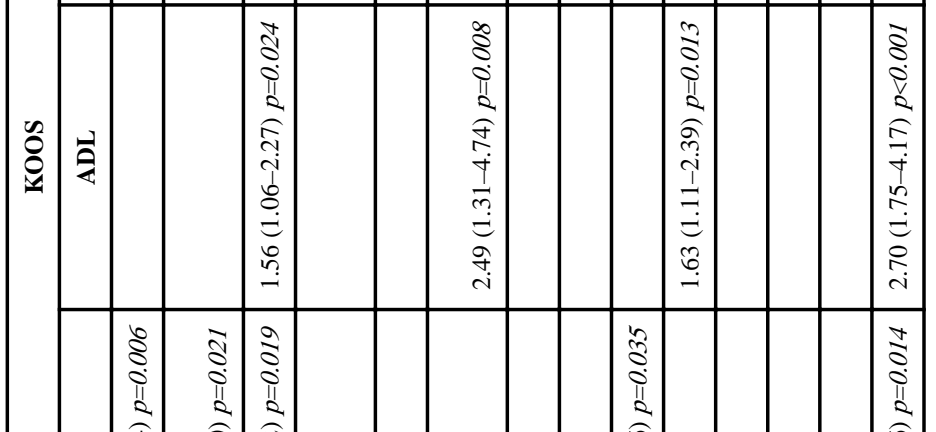

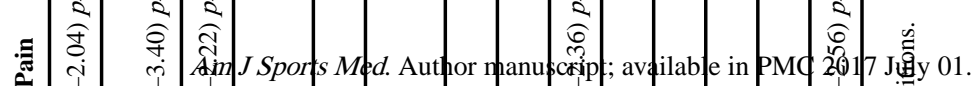

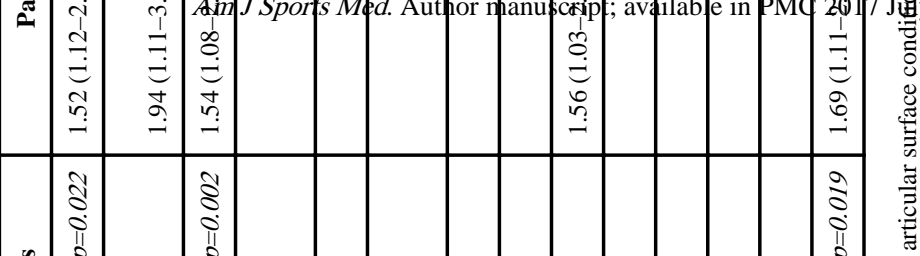

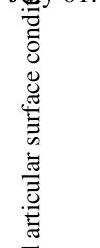


Page 17

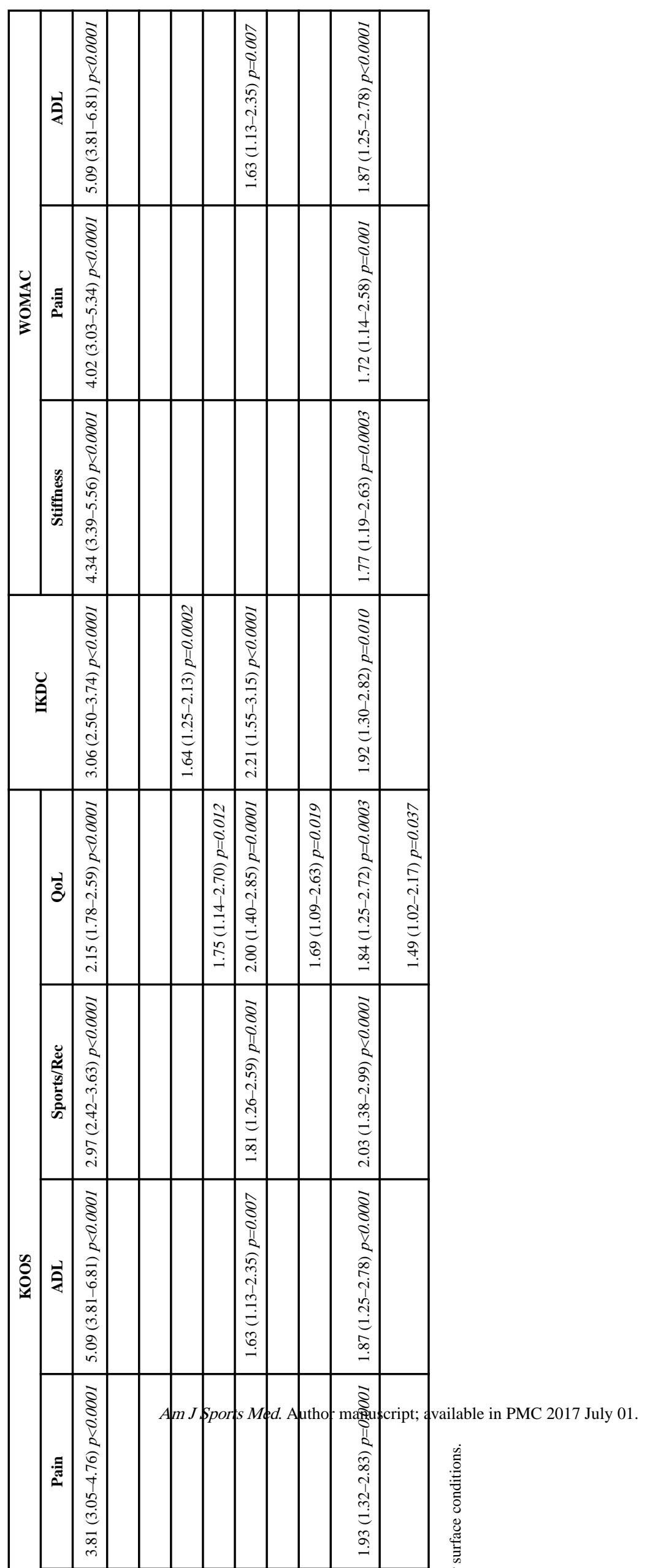

